05

\title{
Анализ условий зарождения зернограничных нанопор В субмикрокристаллических материалах в процессе интенсивной пластической деформации
}

\author{
(C) В.Н. Перевезенцев ${ }^{1,2}$, А.С. Пупынин ${ }^{1, \uparrow}$ \\ ${ }^{1}$ Институт проблем машиностроения РАН, Нижний Новгород, Россия \\ ${ }^{2}$ Нижегородский государственный университет им. Н.И. Лобачевского, Нижний Новгород, Россия \\ E-mail: pupynin.as@gmail.com
}

Поступило в Редакцию 9 июня 2020г.

В окончательной редакции 30 июня 2020 г.

Принято к публикации 1 июля 2020 г.

Предложена модель, позволяющая описать зарождение зернограничных нанопор в субмикрокристаллических материалах в процессе интенсивной пластической деформации. Проанализировано влияние внутренних полей напряжений от планарных мезодефектов, внешнего гидростатического давления и степени пересыщения материала неравновесными вакансиями деформационного происхождения на скорость зарождения пор.

Ключевые слова: субмикрокристаллические металлы, границы зерен, мезодефекты, неравновесные вакансии, нанопоры.

DOI: 10.21883/PJTF.2020.19.50040.18416

Субмикрокристаллические (СМК) материалы, полученные методами интенсивной пластической деформации (ИПД), обладают уникальными физикомеханическими свойствами [1]. Однако после ИПД часто наблюдается снижение долговечности СМК-материалов в условиях длительного нагружения. В работах Бетехтина и соавторов [2-4] показано, что этот эффект может быть связан с наличием в исходном состоянии в СМК-материалах нанопор, расположенных на границах зерен (ГЗ) и в тройных стыках (ТС) зерен. Согласно [4], в процессе ползучести СМК-материалов при повышенной температуре определенная доля нанопор развивается в микропоры, создавая тем самым „очаги“ разрушения, снижающие долговечность материала. Нанопоры наблюдались после ИПД в $\mathrm{Al}[5,6], \mathrm{Cu}[7,8], \mathrm{Ti}[9,10]$ и других металлах и сплавах. Однако вопрос о причинах зарождения нанопор при ИПД, протекающей в условиях высокого гидростатического давления, препятствующего порообразованию, до сих пор остается дискуссионным.

Целью настоящей работы является анализ возможности зарождения нанопор на ГЗ в СМК-материалах путем агломерации неравновесных вакансий деформационного происхождения в поле внутренних растягивающих напряжений от мезодефектов, накапливающихся на ГЗ в процессе ИПД $[11,12]$.

В процессе ИПД в объеме зерен поликристалла образуется большое количество неравновесных вакансий деформационного происхождения, характеризуемое величиной пересыщения $S_{v}=C_{v d} / C_{0}$, где $C_{v d}-$ атомная концентрация деформационных вакансий, $C_{0}-$ термодинамически равновесная атомная концентрация решеточных вакансий. Экспериментальные данные показывают, что атомная концентрация неравновесных вакансий в СМК-материалах достигает весьма высоких значений: $C_{v d} \sim 4 \cdot 10^{-4}[13]$. Следует отметить, что в обычных поли- и монокристаллах такие значения концентрации вакансий характерны для температур, близких к температуре плавления.

Образование пор в условиях высокого пересыщения неравновесными вакансиями, возникающими в процессе радиационного облучения, анализировалось в работе [14]. При рассмотрении зарождения пор в СМК-материалах необходимо учесть то обстоятельство, что процесс ИПД осуществляется в условиях гидростатического давления $P_{e}$, препятствующего образованию пор. Однако в процессе деформирования поликристаллов на ГЗ и их морфологических особенностях (стыках, изломах) возникают характерные мезодефекты: стыковые дисклинации и планарные мезодефекты $[11,12]$. Отрицательные стыковые дисклинации и планарные мезодефекты создают мощные поля растягивающих напряжений, которые могут компенсировать внешние сжимающие напряжения и тем самым способствовать диффузионному зарождению и росту пор в области ТС и ГЗ. В настоящей работе рассмотрено влияние планарных мезодефектов на зарождение пор на ГЗ. Анализ зарождения пор в ТС в поле дисклинаций будет проведен в последующих публикациях.

Поле гидростатического давления от планарного мезодефекта, представляющего собой однородно распределенные вдоль ГЗ скользящие дислокации (рис. 1), имеет вид [15]:

$P_{i}=(1+v) G \omega_{t}\left[\arctan \left(\frac{y+l}{x}\right)-\arctan \left(\frac{y-l}{x}\right)\right] / 3 \pi(1-v)$,

где $G$ - модуль сдвига, $v$ - коэффициент Пуассона, $2 l$ - длина планарного мезодефекта (далее будем 


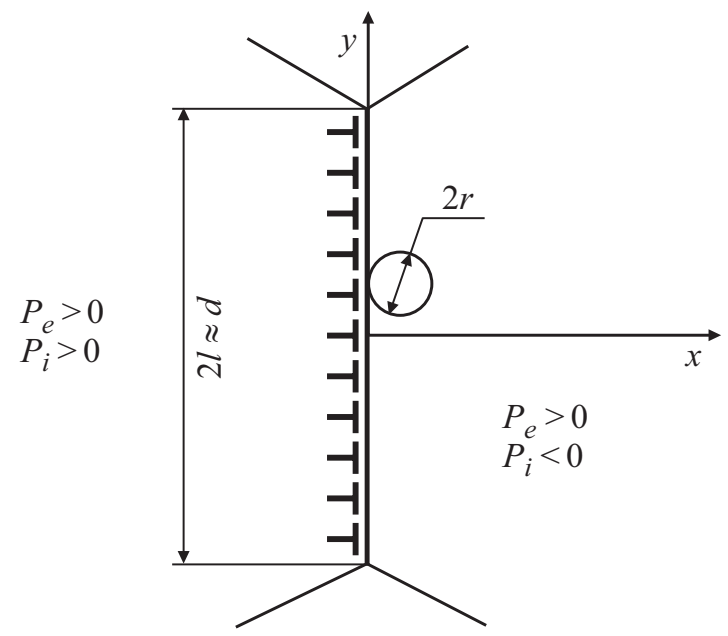

Рис. 1. Схематическое представление зарождения поры на ГЗ, содержащей планарный мезодефект.

считать ее по порядку величины близкой к размеру зерна $d), \omega_{t}=\rho_{b} \Delta b_{t}, \rho_{b}-$ плотность дислокаций ориентационного несоответствия, накапливающихся в границах зерен в процессе пластической деформации, $\Delta b_{t}$ - тангенциальная составляющая их вектора Бюргерса. Как видно из выражения (1), при $y<l$ в области $x>0$ создается область растяжения, при $x<0-$ зона сжатия (рис. 1). В приграничном слое $0<x<2 r$ величина $P_{i} \approx-(1+v) G \omega_{t} / 3(1-v)$. При экспериментально наблюдаемой экстремально высокой плотности дислокаций в ГЗ $\rho_{b} \approx 2 \cdot 10^{8} \mathrm{~m}^{-1}$ величина $\omega_{t} \approx 3 \cdot 10^{-2}$ и, следовательно, $\left|P_{i}\right| \approx 2 \cdot 10^{-2} G$.

В области сжатия, где давление $P_{i}$ совпадает по знаку с внешним давлением, процесс образования пор подавляется. В то же время в области растяжения внутреннее давление компенсирует внешнее, облегчая тем самым зарождение пор.

Учитывая отмеченное выше, изменение энергии системы при слиянии $n$ неравновесных вакансий в пору, расположенную на ГЗ (рис. 1), можно записать в виде

$$
\Delta F=-n\left(k T \ln \left(S_{v}+1\right)-P_{e f f} \Omega\right)-\pi r_{b}^{2} \gamma_{b}+4 \pi r^{2} \gamma_{s},
$$

где первое слагаемое описывает изменение энергии за счет уменьшения химического потенциала вакансий, второе слагаемое - изменение энергии за счет уменьшения поверхностной энергии ГЗ, третье слагаемое связано с затратами энергии на образование свободной поверхности (СП). Здесь $P_{e f f}=P_{e}-P_{i}$, $\gamma_{b}$ и $\gamma_{s}$ - удельные энергии ГЗ и СП соответственно; $r \approx(3 n \Omega / 4 \pi)^{1 / 3}-$ радиус поры, $r_{b}$ - размер области контакта поры с ГЗ. Величину $r_{b}$ можно определить исходя из условия механического равновесия поры с ГЗ:

$$
r_{b}=r \sqrt{1-\left(1-\gamma_{b} / \gamma_{s}\right)^{2}}
$$

При дальнейших расчетах мы учли то обстоятельство, что при малых размерах зародыша поры энергия ее
СП зависит от размера поры (числа вакансий $n$, коагулирующих в пору). Для описания этой зависимости использовалось выражение [16]:

$$
\gamma_{s}=\gamma_{s 0}(1-0.8 /(n+2)),
$$

где $\gamma_{s 0}$ - энергия плоской СП. Критический размер зародыша поры $r_{c}$ находился из условия $\partial \Delta F / \partial n=0$. Энергия образования критического зародыша $\Delta F_{c}$ определялась путем подстановки величины $r_{c}$ в выражение (2).

Скорость зарождения пор в единице объема $J_{c}$ находилась из выражения [17]:

$$
J_{c}=Z\left(N_{0}-C_{c a v}\right) \beta_{c} \exp \left(-\Delta F_{c} / k T\right),
$$

где $Z \approx 1 / 20$ - фактор Зельдовича, $N_{0}=3 / \pi r_{c} d^{2}-$ максимальная концентрация центров зарождения в ГЗ, $C_{c a v}-$ концентрация зародышей пор, $\beta_{c}-$ скорость присоединения вакансии к зародышу критического размера [17],

$$
\beta_{c}=4 \pi D_{l}\left(S_{v}+1\right)\left(r_{c}+b\right)^{2} / b^{4} .
$$

Здесь $D_{l}=D_{l 0} \exp \left(-Q_{l} / k T\right)-$ коэффициент объемной самодиффузии, $Q_{l}$ - энергия активации объемной самодиффузии. Для анализа кинетики эволюции пористости при ИПД систему уравнений $(1)-(6)$ следует дополнить уравнениями, описывающими диффузионный рост пор и изменение пересыщения материала неравновесными вакансиями, связанное с генерацией деформационных вакансий и их стоком в зарождающиеся и растущие поры. В настоящей работе мы ограничились анализом скорости образования зародышевых нанопор. Анализ эволюции объемной доли и размеров пор будет проведен в последующих публикациях.

Численные расчеты скорости зарождения нанопор проводились для модельного алюминиевого СМК-сплава с размером зерна $d=10^{-6} \mathrm{~m}$ при температурах деформации $T_{1}=0.3 T_{m}$ и $T_{2}=0.4 T_{m}$, значениях внешнего гидростатического давления $P_{e 1}=1.5 \cdot 10^{-2} G$ и $P_{e 2}=10^{-2} G$ и следующих характерных значениях параметров: $C_{v d}=4 \cdot 10^{-4}, T_{m}=933 \mathrm{~K}, b=2.86 \cdot 10^{-10} \mathrm{~m}$, $G=25 \mathrm{GPa}, \gamma_{s 0} \approx G b / 16, \Omega \approx b^{3}, D_{l 0}=9 \cdot 10^{-5} \mathrm{~m}^{2} / \mathrm{s}$, $Q_{l}=17.4 k T_{m}$. Рис. 2 иллюстрирует поведение скорости зарождения пор $J_{c 0}$ и объема критических зародышей пор $V_{c 0}$ в зависимости от степени пересыщения материала вакансиями при выбранных значениях внешнего давления $P_{e}$ и температуры. При проведении расчетов нижняя граница интервала значений пересыщения $S_{v 0}$ выбиралась таким образом, чтобы обеспечить зарождение на каждой границе зерна как минимум одной поры.

Из представленных зависимостей видно, что уменьшение внешнего гидростатического сжатия $P_{e}$, увеличение степени пересыщения $S_{v 0}$ и температуры деформации приводит к существенному увеличению скорости зарождения (рис. 2,a), а также к уменьшению объема критических зародышей пор (рис. 2,b). 

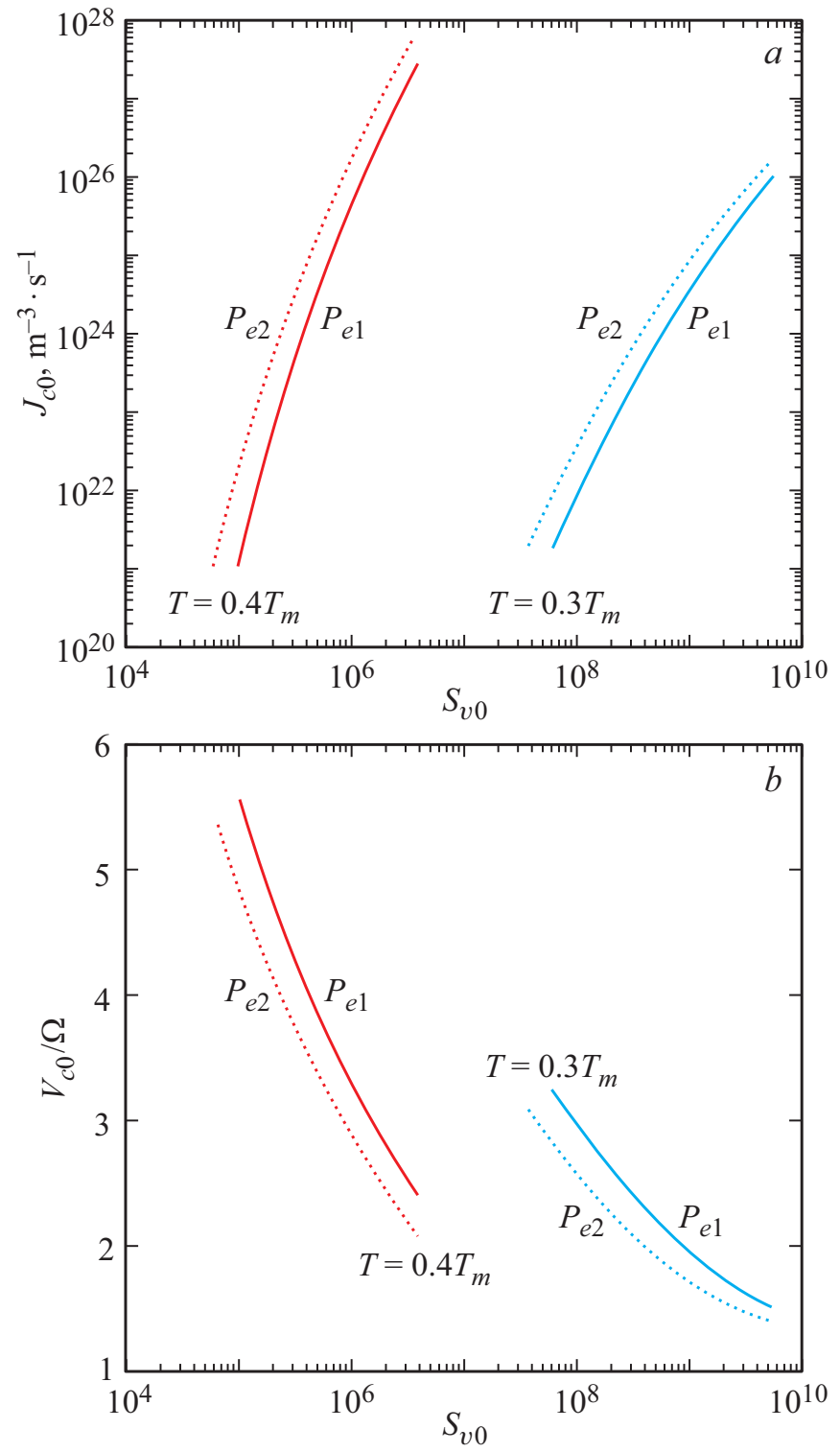

Рис. 2. Зависимости скорости зарождения пор $J_{c 0}(a)$ и объема критических зародышей пор $V_{c 0}(b)$ от степени пересыщения $S_{v 0}$ при заданных значениях гидростатического давления $P_{e}$ и температуры деформации $T$.

Проведенный анализ показывает возможность диффузионного зарождения нанопор на ГЗ СМК-материалов. Установлено, что зарождение нанопор в условиях характерных для ИПД высоких значений гидростатических давлений может осуществляться в зонах растягивающих напряжений от планарных мезодефектов, формирующихся в ГЗ при пластической деформации. Условием появления таких нанопор является высокая степень пересыщения материала неравновесными вакансиями деформационного происхождения. Эффективным способом подавления диффузионного зарождения пор при ИПД является повышение внешнего гидростатического давления и понижение температуры деформации.

\section{Финансирование работы}

Исследование выполнено при финансовой поддержке Российского фонда фундаментальных исследований в рамках научного проекта № 20-08-00867.

\section{Конфликт интересов}

Авторы заявляют, что у них нет конфликта интересов.

\section{Список литературы}

[1] Valiev R.Z., Langdon T.G. // Prog. Mater. Sci. 2006. V. 51. N 7. P. 881-981. DOI: $10.1016 /$ j.pmatsci.2006.02.003

[2] Бетехтин В.И., Колобов Ю.P., Sklenicka V., Кадомцев А.Г., Нарыкова М.В., Dvorak J., Голосов Е.В., Кардашев Б.К., Кузьменко И.Н. // ЖТФ. 2015. Т. 85. В. 1. С. 66-72. http://journals.ioffe.ru/articles/41253

[3] Бетехтин В.И., Sklenicka V., Кадомиев А.Г., Колобов Ю.Р., Нарыкова М.В. // ФТТ. 2017. Т. 59. В. 5. С. 935-941. DOI: $10.21883 /$ FTT.2017.05.44383.391

[4] Бетехтин В.И., Кадомцев А.Г., Нарыкова М.В. // ФТТ. 2020. T. 62. B. 2. C. 267-273.

DOI: $10.21883 /$ FTT.2020.02.48878.603

[5] Бетехтин В.И., Кадомиев А.Г., Sklenicka V., Saxl I. // ФТТ. 2007. T. 49. В. 10. С. $1787-1790$.

http://journals.ioffe.ru//articles/3184

[6] Бетехтин В.И., Sklenicka V., Saxl I., Кардашев Б.К., Кадомиев А.Г., Нарыкова М.В. // ФТТ. 2010. Т. 52. В. 8. C. 1517-1523. http://journals.ioffe.ru/articles/1925

[7] Sauvage X., Pippan R. // Mater. Sci. Eng. A. 2005. V. 410411. P. 345-347. DOI: 10.1016/j.msea.2005.08.122

[8] Ribbe J., Baither D., Schmitz G., Divinski S.V. // Scripta Mater. 2009. V. 61. P. $129-132$.

DOI: $10.1016 /$ j.scriptamat.2009.03.029

[9] Lapovok R., Tomus D., Mang J., Estrin Y., Lowe T.C. // Acta Mater. 2009. V. 57. N 10. P. 2909-2918.

DOI: $10.1016 /$ j.actamat.2009.02.042

[10] Бетехтин В.И., Колобов Ю.Р., Нарыкова М.В., Кардашев Б.К., Голосов Е.В., Кадомиев А.Г. // ЖТФ. 2011. Т. 81. B. 11. C. 58-63. http://journals.ioffe.ru/articles/10459

[11] Rybin V.V., Zisman A.A., Zolotorevsky N.Yu. // Acta Met. Mater. 1993. V. 41. N 7. P. 2211-2217. DOI: 10.1016/0956-7151(93)90390-E

[12] Кириков С.В., Перевезенцев В.Н., Свирина Ю.В. // Деформация и разрушение материалов. 2018. № 3. С. 20-25. https://elibrary.ru/item.asp?id $=32595898$

[13] Schafler E., Steiner G., Korznikova E., Kerber M., Zehetbauer M.J. // Mater. Sci. Eng. A. 2005. V. 410-411. P. 169-173. DOI: 10.1016/j.msea.2005.08.070

[14] Powell R.W., Russell K.C. // Rad. Effects. 1972. V. 12. N 1-2. P. 127-131. DOI: 10.1080/00337577208231129

[15] Perevezentsev V.N., Sarafanov G.F. // Rev. Adv. Mater. Sci. 2012. V. 30. N 1. P. 73-89. http://www.ipme.ru/ejournals/RAMS/no_13012/04_perevezentsev.pdf

[16] Черемской П.Г., Слезов В.В., Бетехтин В.И. Поры в твердом теле. М.: Энергоатомиздат, 1990. 376 c.

[17] Raj R., Ashby M.F. // Acta Met. 1975. V. 23. N 6. P. 653-666. DOI: 10.1016/0001-6160(75)90047-4 